
\title{
CIÊNCIANATURA
}

\section{Naturalidade da paisagem do município de Luís Antônio, São Paulo}

\author{
Landscape naturalness of the municipality of Luís Antônio, São Paulo
}

\author{
Karielle Ferreira da Silva ${ }^{1 *}$, Mariana Dorici ${ }^{2}$, Dayana Almeida ${ }^{3}$, Lucas Sueishi Morales ${ }^{4}$ \\ e Luiz Eduardo Moschini ${ }^{5}$
}

\begin{abstract}
${ }^{1,4}$ Discente do curso de Bacharelado em Gestão e Análise Ambiental da Universidade Federal de São Carlos SP, Brasil ${ }^{2}$ Doutoranda do Programa de Pós-Graduação em Ciências Ambientais da Universidade Federal de São Carlos SP, Brasil ${ }^{3}$ Pesquisadora do Programa de Pós-Graduação em Ciências Ambientais da Universidade Federal de São Carlos SP, Brasil

${ }^{5}$ Docente do Programa de Pós-Graduação em Ciências Ambientais da Universidade Federal de São Carlos SP, Brasil
\end{abstract}

\section{Resumo}

As ações antrópicas vêm causando danos severos ao meio ambiente, fazendo com que surgissem, como estratégia de conservação de áreas naturais, Unidades de Conservação como a Estação Ecológica de Jatai (EEJ), em Luís Antônio-SP. A EEJ protege um dos mais singulares fragmentos de Cerrado e de Floresta Estacional e ecotonal do estado, abrigando espécies endêmicas e ameaçadas de extinção e encontra-se inserida em um território de grandes pressões antrópicas. Nesse sentido, o presente trabalho teve como propósito diagnosticar a naturalidade da paisagem do município de Luís Antônio - SP mediante a aplicação do Índice de Urbanidade (IB). Foi analisada a dinâmica de uso e cobertura do solo para 2007 e 2017 e percebeu-se a diminuição de 45,52\% da classe Água, a perda de 8,26\% da Área de vegetação natural e um aumento expressivo de Áreas antrópicas agrícolas (5,39\%) e Áreas antrópicas não agrícolas (6,42\%). As classes com menor naturalidade da paisagem (Classe 1, 2 e 3) ocupam 68,87\% enquanto que as classes de maior naturalidade (Classe 4 e 5) 31,13\% do municipio. Promover o entendimento da naturalidade da paisagem, é de suma importância no sentido de proporcionar a conscientização sobre os problemas ambientais e de identificar áreas relevantes para conservação.

Palavras-chave: Índice de Urbanidade; EEJ; SIG

\section{Abstract}

Antropic actions have been causing severe damage to the environment. In this sense, Protected Area are an important conservation strategy for natural areas, such as the Jatai Ecological Station (EEJ), in Luís AntônioSP. The EEJ protects one of the most unique fragments of Cerrado and Seasonal Forest and Ecotonal System of the State, housing endemic and endangered species and it is located in a territory of great anthropic pressures. The present work had as its purpose to diagnose the natural landscape of the municipality of Luís Antônio - SP by applying the Urbanity Index (IB). The dynamics of land use and cover for 2007 and 2017 were analyzed and was observed the reduction of $45.52 \%$ of the class Water, the loss of $8.26 \%$ of the Area of natural vegetation and an expressive increase of anthropic agricultural areas (5.39\%) and non-agricultural anthropic areas (6.42\%). Class with less natural landscape (Class 1, 2 and 3) occupy 68.87\% while the most natural classes (Class 4 and 5) 31.13\% of Luís Antônio municipality. To promote the understanding of the landscape's naturalness, is of paramount importance in the sense of providing awareness about environmental problems and of identifying relevant areas for conservation.

Keywords: Urbanity Index; EEJ;GIS

* karielleferreira@gmail.com 


\section{Introdução}

\section{Introdução}

As paisagens são moldadas pelas intervenções e alterações das sociedades humanas, que representam sua cultura e simbolismo no ambiente onde vivem, criando mosaicos de diferentes tamanhos, formas e disposições (SANTOS, 1985; TURNER, 1989; OST, 1998; BALIM et al., 2014). As mudanças nas paisagens, são inevitáveis (TEIXEIRA, et al., 2009), portanto, é de grande valia, entender a dinâmica temporal de determinada área ao longo do tempo, realizando o diagnóstico e caracterização das modificações de seu uso e ocupação.

Apesar do nítido aumento dos níveis de desenvolvimento econômico e social adquiridos nos últimos anos, percebe-se que a ação antrópica vem causando, seja por conta de atividades agrícolas, industriais ou pelo processo acelerado de urbanização, danos irreversíveis aos ecossistemas e aos ambientes naturais (EHRLICH; MOONEY, 1983; MARTINE; ALVES 2015).

Com o intuito de suprir suas demandas e necessidades, as atividades humanas têm causado a degradação e perda dos serviços ambientais que na maioria das vezes são utilizados de forma insustentável, não respeitando a capacidade de recuperação natural dos processos ecológicos dos ecossistemas (MILLENIUM ECOSYSTEM ASSESSMENT, 2005; CAVENDER-BARES et al., 2015; DEBOLINI et al., 2015).

A conversão de áreas nativas intensificada pelas pressões antrópicas, têm desencadeado um processo de fragmentação das paisagens e causado impactos significativos à biodiversidade, à provisão dos serviços ecossistêmicos e consequentemente a qualidade de vida e bem-estar humano, comprometendo as condições de vida adequadas para as gerações futuras (DE GROOT et al., 2002; JAX et al., 2013; COELHO et al., 2014; ANDRADE; ROMEIRO, 2011).

Acompanhando o aumento da preocupação quanto às questões ambientais, foram criadas as Unidades de Conservação (UCs), que são áreas protegidas direcionadas à utilidade pública e que representam uma importante estratégia para conservação dos recursos naturais, de culturas associadas (MEDEIROS; PEREIRA, 2011) e da biodiversidade, tendo por objetivo a proteção ambiental (SANTOS, 2011; BRASIL, 2000).

Uma UC de fundamental importância para todo estado de São Paulo é a Estação Ecológica de Jataí (EEJ), com uma área de aproximadamente 8.798,37 ha, protegendo em seu território um dos mais singulares fragmentos de Cerrado e de floresta estacional semidecidual e ecótono Cerrado/florestal estacional semidecidual do estado, abrigando espécies endêmicas e ameaçadas de extinção. Além da grande biodiversidade, suas paisagens são esculpidas pela variedade de solos, de relevo e de altitudes, características pouco comuns nas áreas protegidas do interior do estado de São Paulo (TOPPA, 2004; FUNDAÇÃO FLORESTAL, 2013).

Esse cenário de diversidade ecológica pode ser considerado um dos principais motivos por ter feito da EEJ uma das UCs de relevante interesse por parte da comunidade científica. O resultado é expresso pelo alto número de estudos e pesquisas desenvolvidas e de um arcabouço solidamente estruturado (FUNDAÇÃO FLORESTAL, 2013).

Localizada no município de Luís Antônio, a EEJ encontra-se inserida em um território onde pressões originadas em seu entorno precisam ser consideradas e analisadas. Atividades econômicas predominantemente agrícolas compõem o seu entorno, além das atividades de extração mineral e a pesca esportiva, o cultivo da cana-de-açúcar, a silvicultura e a citricultura (FUNDAÇÃO FLORESTAL, 2013).

Nesse sentido, o presente trabalho tem como propósito diagnosticar a naturalidade da paisagem do município de Luís Antônio - SP mediante a aplicação do Índice de Urbanidade (IB). 


\section{Materiais e métodos}

\subsection{Caracterização da área de estudo}

O município de Luís Antônio localiza-se na região metropolitana de Ribeirão Preto no interior do estado de São Paulo, a aproximadamente $275 \mathrm{~km}$ da capital paulista, entre as coordenadas geográficas $21^{\circ} 33^{\prime} 18^{\prime \prime}$ latitude sul e 4742'16" longitude oeste, e apresenta uma altitude de $675 \mathrm{~m}$. Luís Antônio faz divisa com os municípios de Cravinhos, Descalvado, Guatapará, Rincão, Santa Rita do Passa Quatro, São Carlos e São Simão (Figura 1).

Figura 1 - Localização geográfica do município de Luís Antônio

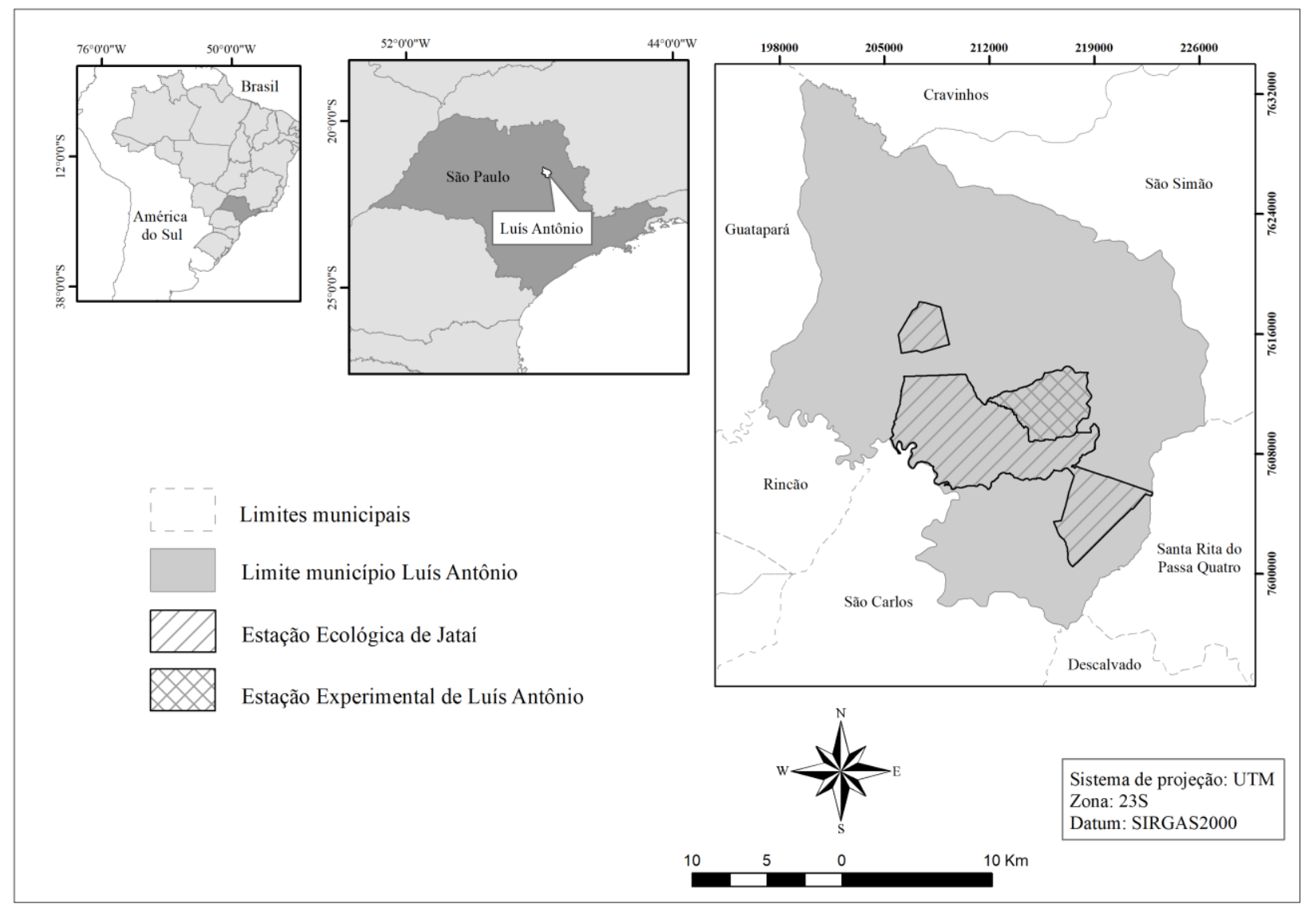

Segundo a projeção demográfica realizada no ano de 2017, pelo Instituto Brasileiro de Geografia e Estatística (IBGE), o município possui uma população estimada em 14.021 pessoas, distribuídos em uma área de 59900,66 ha, o que corresponde a uma densidade demográfica de $18,85 \mathrm{hab} . / \mathrm{km}^{2}$.

Sua economia conta com atividades agrícolas e agroindústrias na produção de açúcar, álcool, celulose e papel. A Indústria contribui com a maior porcentagem do Produto Interno Bruto (PIB), cerca de 56,56\%, seguida pelo setor de Serviços $(19,91 \%)$ e Agropecuária (7,47\%), o restante destina-se a Impostos $(10,83 \%)$ e a Administração e Serviços Públicos (5,22\%) (IBGE, 2010).

A vegetação natural original de Luís Antônio é composta, principalmente, por Cerrado e floresta estacional semidecidual, das quais grande parte já foi desmatada. Atualmente, predominam áreas de mata ripária, vegetação de colina e remanescentes de Cerrado, sendo que a EEJ tem grande responsabilidade na manutenção dessas áreas (SANTOS, 2001). 
A EEJ abriga diferentes fitofisionomias de Cerrado em contato com floresta estacional semidecidual, caracterizando-se como um sistema ecotonal único, encontrado na região tropical. Praticamente inexistem UCs nestes sistemas, o que torna a EEJ uma das únicas grandes áreas remanescentes da região, e portanto, de extrema importância para a conservação (TOPPA, 2004; FUNDAÇÃO FLORESTAL, 2013). Ademais, a Estação Experimental de Luís Antônio, adjunta a EEJ, realiza programas e atividades de pesquisas científicas com espécies nativas e exóticas (Pinus spp. e Eucalyptus spp.) para produção vegetal (SANTOS, 2001).

\subsection{Procedimentos metodológicos}

Para este trabalho, foram elaborados Planos de Informação no Sistema de Projeção Geográfica UTM - Fuso 23S, Datum SIRGAS2000 (BRASIL, 2005), através da utilização de imagens dos satélites Landsat 5 e Landsat 8 , respectivamente, dos anos de 2007 e 2017 (UNITED STATES, 2017), para posterior inserção e análise com o auxílio do software $\operatorname{ArcGis}{ }^{\circledR} 10.5$ (Tabela 1).

Tabela 1 - Planos de informação utilizados na análise

\begin{tabular}{|c|c|c|}
\hline Material & Descrição & Fonte \\
\hline Uso e cobertura do solo 2007 & \multirow{2}{*}{$\begin{array}{c}\text { Classes de uso e } \\
\text { cobertura do } \\
\text { solo }\end{array}$} & $\begin{array}{l}\text { Imagem LandSat } 5, \text { órbita/ponto } 220 / 75 \text { de } \\
\text { 03/05/2007. Composição colorida - bandas: } 5,4 \text { e } 3\end{array}$ \\
\hline Uso e cobertura do solo 2017 & & $\begin{array}{l}\text { Imagem Landsat } 8, \quad \text { órbita/ponto } 220 / 75 \text { de } \\
\text { 23/02/2017. Composição colorida - bandas } 6,5,4\end{array}$ \\
\hline
\end{tabular}

Os procedimentos para realização dessa análise incluíram a categorização do uso e cobertura do solo, nos anos de 2007 e 2017, segundo os critérios de classificação do Manual Técnico do Uso da Terra (IBGE, 2013), que engloba três níveis hierárquicos de classificação, sendo eles: Classe, Subclasse e Unidades. No trabalho utilizamos apenas a classificação por Classe, por oferecer o nível de detalhamento necessário para aplicação do índice de urbanidade, essa classificação e a alimentação do banco de dados foi feita de forma manual.

O diagnóstico da naturalidade da paisagem se deu a partir da aplicação do Índice de Urbanidade (IB), desenvolvido por O' Neil et al. (1998). Tal índice, é utilizado para mensurar a intensidade e extensão em que as paisagens são dominadas por sistemas alterados pela interferência antrópica, sendo um indicador da naturalidade da mesma (WRBKA et al, 2004; TREVISAN et al., 2017), que pode ser descrito conforme a equação a seguir:

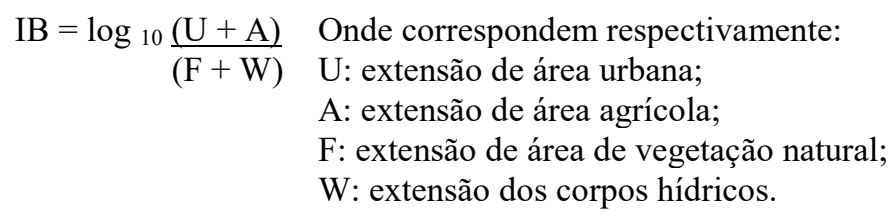

Para representação do IB utilizamos a Lógica Fuzzy, que consiste em uma variação da lógica booleana, onde realiza-se a padronização dos critérios de tipo linear $[\mathrm{y}=\mathrm{f}(\mathrm{x})]$, apresentando valores apenas em um intervalo de 0 a 1 (CEREDA JUNIOR, 2011). Consideramos IB $=1$ como valor máximo de naturalidade, relacionando-se com sistemas com menor interferência antrópica, e IB $=0$, como valor mínimo de naturalidade, correspondendo a sistemas com maior interferência antrópica. 


\section{Resultados e discussão}

Com o intuito de alcançar o objetivo proposto neste trabalho, os resultados e discussões foram divididos em dois tópicos. Num primeiro momento foi realizada uma análise multitemporal do uso e ocupação do município de Luís Antônio, considerando o período de 2007 a 2017. Posteriormente, foi discutido o grau de naturalidade da paisagem, por meio da aplicação do Índice de Urbanidade (IB).

\subsection{Análise multitemporal do uso e cobertura do solo}

No período analisado entre 2007 e 2017, foram identificadas e classificadas, no município de Luís Antônio, cinco classes de uso e cobertura do solo: [1] Área de vegetação natural, [2] Áreas antrópicas agrícolas, [3] Áreas antrópicas não agrícolas, [4] Água e [5] Outras áreas (Figura 2).

Figura 2 - Análise da dinâmica temporal do uso e cobertura do solo do município de Luís Antônio, para os anos de 2007 e 2017

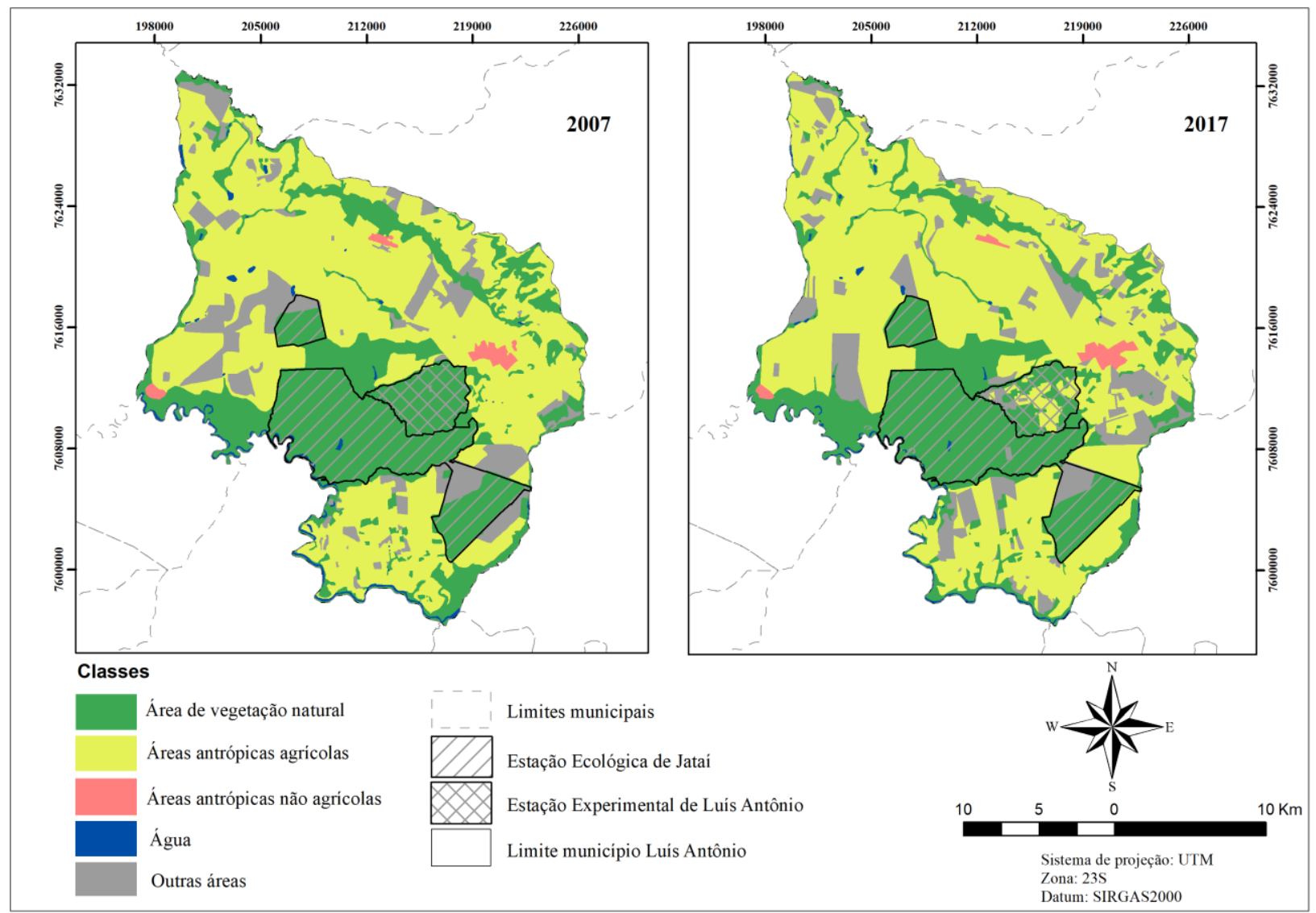

A Área de vegetação natural compreende um conjunto de estruturas florestais originais ou alteradas, em diversos estágios sucessionais de desenvolvimento, distribuídos por diferentes ambientes e situações geográficas. As Áreas antrópicas agrícolas, são terras destinadas à produção de alimentos, fibras e commodities do agronegócio, incluindo todas as terras cultivadas. Encontram-se inseridas nesta categoria as lavouras temporárias, lavouras permanentes, pastagens e silvicultura. Enquanto que as Áreas antrópicas não agrícolas são áreas em que estão associados todos os tipos de uso da terra de natureza não agrícola, florestal ou água, tais como áreas urbanizadas, industriais, comerciais, redes de comunicação e áreas de extração mineral. A classe Água refere-se aos corpos d'água naturais e artificiais que não são de origem marinha, tais como: rios, canais, lagos e lagoas de água doce, represas e 
açudes. E Outras áreas, referem-se a ambientes naturais, como rochas desnudas e a ambientes antrópicos, decorrentes da degradação provocada pelas atividades humanas, como extração de minerais e terra agrícola em descanso.

A classe de Áreas antrópicas agrícolas ocupa mais de 50\% da área total do município de Luís Antônio, sendo o principal fator antrópico de alteração da paisagem no local. A cultura temporária predominante na região é a cana de açúcar, cultivo que vem ganhando, desde 2009, importância no cenário nacional devido ao crescente interesse em se diminuir a dependência de combustíveis fósseis (AGUIAR et al., 2009).

As lavouras de cana de açúcar requerem períodos de descanso (ou pousio) da terra, que se associam a outro fator antrópico determinante na paisagem do município, as áreas classificadas como Outras áreas. Tais áreas, que se distribuem por mais de $11 \%$ do território do município, são em sua maioria terras agrícolas em descanso advindas do cultivo da cana de açúcar.

Destaca-se ainda que, Luís Antônio tem uma quantidade significativa de Área de vegetação natural, cerca de $30 \%$ do total mapeado, em relação às demais classes especializadas. O restante da área corresponde a classe Áreas antrópicas não agrícolas e Água, que juntas ocupam aproximadamente 2\% do município (Tabela 2).

Tabela 2 - Dinâmica do uso e cobertura do solo do município de Luís Antônio, para os anos de 2007 e 2017

\begin{tabular}{|c|c|c|c|c|c|}
\hline \multirow{2}{*}{ Classes } & \multicolumn{2}{|c|}{2007} & \multicolumn{2}{|c|}{2017} & \multirow{2}{*}{$\begin{array}{l}\text { Variação em } \\
10 \operatorname{anos}(\%)\end{array}$} \\
\hline & Área - Hectares (ha) & Porcentagem (\%) & Área - Hectares (ha) & Porcentagem (\%) & \\
\hline Área de vegetação natural & 20551,89 & 34,31 & 18984,04 & 31,69 & $-8,26$ \\
\hline Áreas antrópicas agrícolas & 31360,39 & 52,35 & 33146,48 & 55,34 & 5,39 \\
\hline Áreas antrópicas não agrícolas & 530,95 & 0,89 & 567,38 & 0,95 & 6,42 \\
\hline Água & 780,19 & 1,30 & 536,14 & 0,90 & $-45,52$ \\
\hline Outras áreas & 6677,24 & 11,15 & 6666,62 & 11,13 & $-0,16$ \\
\hline Total (ha) & 59900,66 & 100,00 & 59900,66 & 100,00 & 0,00 \\
\hline
\end{tabular}

Analisando a dinâmica de uso e cobertura do solo para os anos de 2007 e 2017, percebe-se que a ocorrência da diminuição da classe Água é a mais marcante dentre todas as modificações verificadas no município. Apesar de parecer pequena, considerando-se o total de hectares correspondentes ao município como um todo $(0,40 \%)$, essa alteração é bastante significativa, tratando-se de uma perda de $45,52 \%$ da área associada a esta classe, ou seja, da superfície ocupada por corpos d'água naturais e artificiais, como rios e represas, de fundamental importância para abastecimento local.

Outra alteração notável é a perda de 8,26\% da Área de vegetação natural do município, que equivale a uma supressão de 1567,85 hectares de extensão de estruturas florestais, primordiais para manutenção da naturalidade do ambiente.

Dentro da EEJ e da Estação Experimental de Luís Antônio existia 9996,36 ha de Área de vegetação natural em 2007, correspondendo a 92,52\% da área das mesmas e em 2017 esse valor foi decrescido para 9419,22 ha, sendo equivalente a 87,18\% do território das Estações. Constatando uma perda de 577,14 ha, correspondente a uma variação de $6,13 \%$ de Área de vegetação natural de um ano a outro. Ressaltando-se que, a Área de vegetação natural existente nas Estações representa quase $50 \%$ de toda a Área de vegetação natural presente no município.

Houve ainda, um aumento expressivo de Áreas antrópicas agrícolas (5,39\%) e Áreas antrópicas não agrícolas $(6,42 \%)$, que se constituem um dos principais fatores antrópicos transformadores da paisagem e do meio ambiente. Além de uma diminuição ínfima de Outras áreas $(0,16 \%)$. 


\subsection{Análise da naturalidade da paisagem}

Para análise mais concreta do Índice de Urbanidade (IB), os níveis de naturalidade foram agrupados em cinco classes $(1,2,3,4$ e 5), sendo a classe 1 representada pelo valor mínimo de naturalidade, ou seja, locais de maior interferência antrópica e a classe 5 pelo valor máximo de naturalidade, locais de menor interferência antrópica. Devido a aplicação da Lógica Fuzzy, as classes foram representadas em intervalos que variam de 0 a 1 (Tabela 3 e Figura 3).

Tabela 3 - Intervalos Fuzzy para as classes do Índice de Urbanidade

\begin{tabular}{c|l}
\hline Classes & Fuzzy \\
\hline 1 & $0,0-0,2$ \\
\hline 2 & $0,2-0,4$ \\
\hline 3 & $0,4-0,6$ \\
\hline 4 & $0,6-0,8$ \\
\hline 5 & $0,8-1,0$ \\
\hline
\end{tabular}

Figura 3 - Índice de Urbanidade do município de Luís Antônio, para os anos de 2007 e 2017

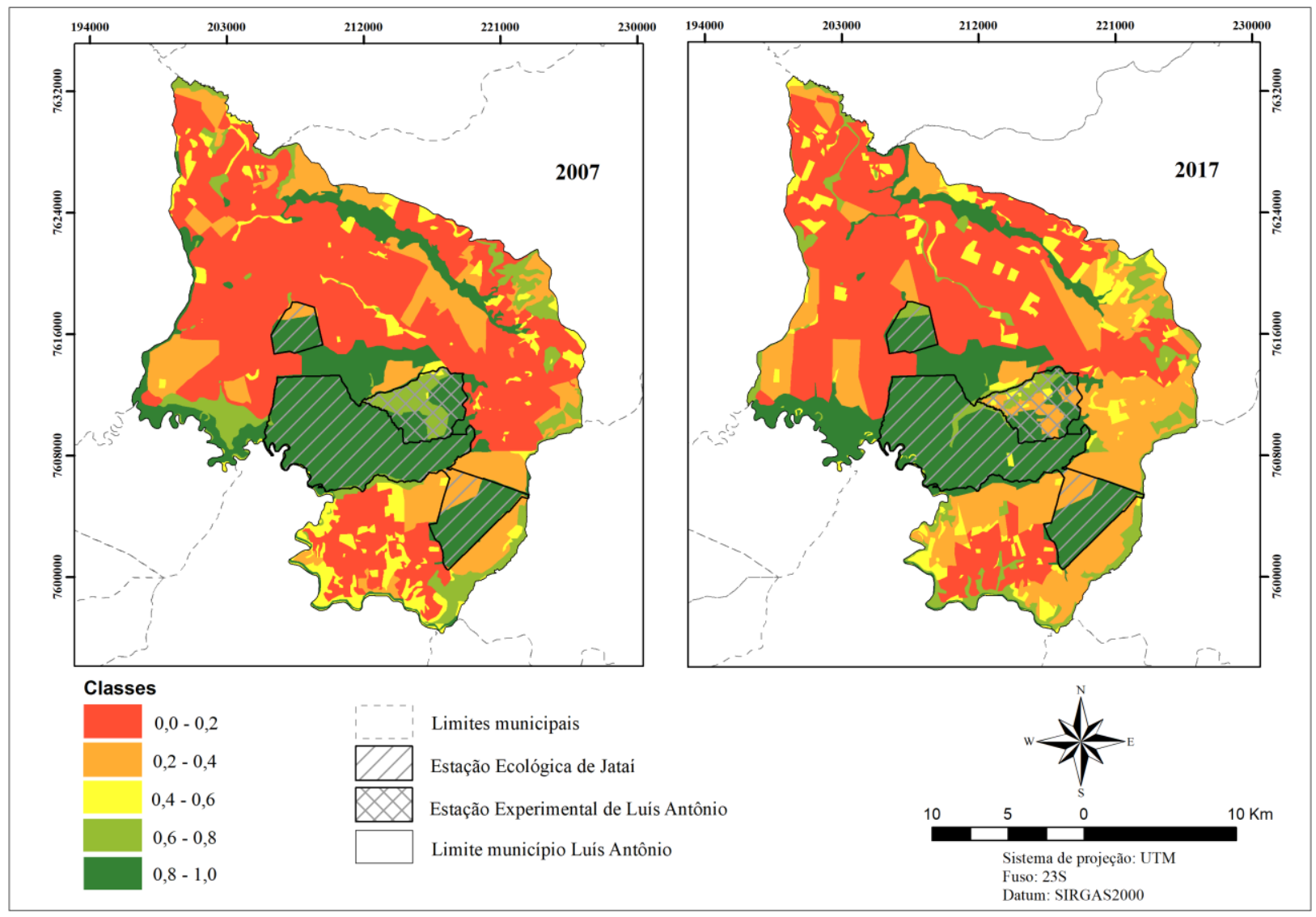

No município de Luís Antônio existe a predominância dos intervalos de menor nível de naturalidade da paisagem, representados pela classe 1 e 2, que correspondem juntos a mais de $60 \%$ do território mapeado. Entretanto a classe 5, que apresenta os maiores níveis de naturalidade e portanto, as áreas menos modificadas pelas atividades antrópicas, também é parte significativa da área do município, constituindo mais de $20 \%$ da mesma. Outros quase $15 \%$ correspondem a níveis intermediários de naturalidade (Tabela 4). 
Tabela 4 - Índice de Urbanidade do município de Luís Antônio, para os anos de 2007 e 2017

\begin{tabular}{|c|c|c|c|c|c|c|}
\hline \multirow{2}{*}{ Classes } & \multirow{2}{*}{ Fuzzy } & \multicolumn{2}{|c|}{2007} & \multicolumn{2}{|c|}{2017} & \multirow{2}{*}{ Variação em 10 anos (\%) } \\
\hline & & Área - Hectares (ha) & Porcentagem (\%) & Área - Hectares (ha) & Porcentagem (\%) & \\
\hline 1 & $0,0-0,2$ & 26966,63 & 45,02 & 22899,51 & 38,23 & $-17,76$ \\
\hline 2 & $0,2-0,4$ & 9398,80 & 15,69 & 13916,06 & 23,23 & 32,46 \\
\hline 3 & $0,4-0,6$ & 4139,64 & 6,91 & 4438,40 & 7,41 & 6,73 \\
\hline 4 & $0,6-0,8$ & 4890,62 & 8,16 & 4284,44 & 7,15 & $-14,15$ \\
\hline 5 & $0,8-1,0$ & 14504,97 & 24,22 & 14362,25 & 23,98 & $-0,99$ \\
\hline Total (ha) & & 59900,66 & 100,00 & 59900,66 & 100,00 & 0,00 \\
\hline
\end{tabular}

A Classe 1 de naturalidade da paisagem encontra-se distribuída por todo o município, associando-se principalmente aos locais ocupados pelas Áreas antrópicas agrícolas, tanto no ano de 2007 (91,74\%) quanto no ano de 2017 (97,24\%). Além disso, estão relacionadas a esta Classe Outras áreas (6,08\% e 0,09\%) e Áreas antrópicas não agrícolas $(1,89 \%$ e $2,47 \%)$, o que corresponde a quase $100 \%$ da área ocupada pelo valor mínimo de naturalidade.

Apesar da Área de vegetação natural e Água, respectivamente, ocuparem juntas 0,27\% e 0,19\% da área, respectivamente, para os anos de 2007 e 2017, as áreas de maior interferência antrópica dominam a Classe 1 de naturalidade. Sabe-se a muito tempo que esses locais podem ser responsáveis por diversos impactos ambientais como erosão do solo, degradação de matas ripárias, perda da biodiversidade e diversos outros, trazendo risco para a qualidade e conservação da porção natural da paisagem, que inclui áreas como a EEJ (PIRES; SANTOS, 1996).

A perda da naturalidade ocasionada pelas atividades antrópicas pode, portanto, levar a uma crise ambiental que associada a fatores estocásticos do meio ambiente prejudique a população de forma direta e/ou indireta, como foi o caso da seca que se sucedeu entre os anos de 2013 e 2014 em todo estado de São Paulo, deixando muitas localidades desprovidas de abastecimento de água (COSTA et al., 2015).

A Classe 2, encontra-se distribuída por todo o município, concentrando-se de forma mais evidente na região sudeste do mesmo. Esta classe também é caracterizada por um alto nível de interferência antrópica, porém menor que o da Classe 1, associando-se principalmente a Áreas antrópicas agrícolas, tanto no ano de 2007 (58,84\%) quanto no ano de 2017 (66,8\%).

Além disso, possuí uma quantidade significativa de Outras áreas em seu território, sendo 40,62\% e 32,91\% para os anos de 2007 e 2017, respectivamente, tratando-se estas principalmente de terras agrícolas em descanso. Somando-se as áreas de interferência antrópica supracitadas, encontram-se as Áreas antrópicas não agrícolas, que ocupam $0,21 \%$ e $0,01 \%$, em 2007 e 2017.

Enquanto que as áreas consideradas naturais, Água e Área de vegetação natural, ocupam juntas cerca de $0,31 \%$ para 2007 e 0,27\% para 2017, evidenciando a baixa naturalidade presente nesta Classe, que junto a Classe 1 corresponde aos menores níveis de naturalidade da paisagem do município de Luís Antônio, corroborando com o surgimento de impactos ambientais.

A Classe 3, está distribuída de forma mais pontual na área de estudo, ocupando principalmente a região sul em 2007 e distribuindo-se de forma mais homogênea por todo o município em 2017. Nesta classe, predomina a Área de vegetação natural (45,36\%) e Outras áreas (29,13\%) em 2007, enquanto que em 2017 predominam Outras áreas (46,26\%), aduzindo a perda de naturalidade da paisagem do ano de 2007 para o ano de 2017, onde a Área de vegetação natural ocupa $19,1 \%$. 
Apesar disso, existe uma grande quantidade de Áreas antrópicas agrícolas tanto para 2007 (24,72\%) quanto para 2017 (34,12\%), sendo as Áreas antrópicas não agrícolas ínfimas ou inexistentes, correspondendo a 0,01\% em 2007 e 0\% em 2017 e a Água correspondente a 0,53\% e 0,32\% para 2007 e 2017.

A Classe 4, distribui-se homogeneamente por todo o município, possuindo áreas significativas nas regiões próximas a EEJ e dentro da Estação Experimental de Luís Antônio. Esta classe é composta predominantemente por Área de vegetação natural nos dois anos, referindo-se a 95,26\% e 95,18\%. Enquanto que, a Água ocupa 3,92\% e 3,59\%, as Áreas antrópicas agrícolas $0,51 \%$ e $0,78 \%$ e as Outras áreas $0,13 \%$ e 0,17\%, para os anos de 2007 e 2017 , respectivamente. Apesar do alto nível de naturalidade da paisagem inferido por esta Classe, a extensão ocupada pela mesma não é tão expressiva quanto a da Classe 5.

A Classe 5, representa o maior nível de naturalidade da paisagem existente no município, porém, encontra-se mais concentrada dentro da Unidade de Conservação e nas regiões circunvizinhas, incluindo a Estação Experimental de Luís Antônio.

Em sua amplitude ocorre prevalentemente a Área de vegetação natural, representando 95,83\% em 2007 e 97,23\% em 2017, seguida pela Água com 3,81\% e 2,48\%, Áreas antrópicas agrícolas com 0,24\% e 0,18\% e Outras áreas com $0,04 \%$ nos dois anos.

Nesse sentido, destaca-se a importância da conservação da EEJ e da Estação Experimental para o município de Luís Antônio, pois estas áreas naturais contribuem para manutenção da naturalidade da paisagem que fornece serviços ecossistêmicos de provisão, regulação, suporte e culturais essenciais para qualidade de vida e bem estar da população e também para o equilíbrio ecológico (DE GROOT et al., 2002; GÓMEZ-BAGGETHUN; DE GROOT, 2010).

\section{Considerações finais}

O município de Luís Antônio apresentou, de maneira geral, baixos níveis de naturalidade da paisagem, sendo que $38,23 \%$ da área é ocupada pela Classe 1,23,23\% pela Classe 2, 7,41\% pela Classe 3.

Nestas áreas, predominam os cultivos agrícolas e as áreas urbanizadas que causam pressões sobre o meio ambiente e suas áreas naturais, que ocorrem associadas, principalmente a Classe 4 que ocupa 7,15\% e a Classe 5 com $23,98 \%$, no território. Estas classes representam os mais altos níveis de naturalidade, que também configuram parte significativa da paisagem de Luís Antônio e estão principalmente associadas a Estação Ecológica de Jataí e a Estação Experimental de Luís Antônio adjacente a ela, que são um impedimento ao agravamento dos impactos ambientais pelas atividades antrópicas atuantes na região.

Reforça-se, portanto, a importância de estudos que promovam o entendimento do estado de conservação e naturalidade de diferentes municípios, a fim de proporcionar o debate e conscientização dos problemas ambientais que as ações antrópicas vêm ocasionando e que seja capaz de identificar áreas relevantes para conservação e manutenção da naturalidade.

Nesse sentido, destaca-se que a metodologia utilizada foi coerente e satisfatória para realização da análise da naturalidade da paisagem e capaz de oferecer subsídios para o planejamento ambiental e a tomada de decisão.

\section{Agradecimentos}

O presente trabalho foi realizado com apoio da Coordenação de Aperfeiçoamento de Pessoal de Nível Superior - Brasil (CAPES) - Código de Financiamento 001. 


\section{References}

AGUIAR DA, SILVA WF, RUDORFF BFT, SUGAWARA LM, CARVALHO MA. Expansão da cana-de-açúcar no Estado de São Paulo: safras 2003/2004 a 2008/2009. In: Anais XIV Simpósio Brasileiro de Sensoriamento Remoto [Internet]; 2009 Abril 25-30; Natal, Brasil, 2009 [cited 2018 Jun 12]. Available from: http://marte.sid.inpe.br/col/dpi. inpe.br/sbsr@80/2008/11.17.18.21/doc/9-16.pdf.

ANDRADE DC, ROMEIRO AR. Degradação ambiental e teoria econômica: algumas reflexões sobre uma "Economia dos Ecossistemas". Revista Economia. 2011;12(1):3-26.

BALIM APC, MOTA LR, SILVA MBO. Complexidade Ambiental: o repensar da relação homem-natureza e seus desafios na sociedade contemporânea. Veredas do Direito. 2014;11(21):163-186.

CAVENDER-BARES J, POLASKY S, KING E, BALVANERA P. [A sustainability framework for assessing trade-offs in ecosystem services]. Ecology and Society [Internet]. 2015 [cited 2018 Jun 12];20:1-17. English. Available from: http://dx.doi.org/10.5751/ES-06917-200117.

CEREDA JUNIOR A. Análise de fragilidade ambiental com métodos multicritério - Críticas e proposta metodológica [thesis]. São Carlos: Programa de Pós-Graduação em Engenharia Urbana/UFSCar; 2011. 147f.

COELHO VHR, MONTENEGRO SMGL, ALMEIDA CN, LIMA VER, NETO AR, MOURA GSS. Dinâmica do uso e ocupação do solo em uma bacia hidrográfica do semiárido brasileiro. Rev. bras. eng. agríc. ambient. 2014;18(1): 64-72.

COSTA CW, PIGA FG, DE MORAES MCP, DORICI M, SANGUINETTO EC, LOLLO JÁ, et al. Fragilidade ambiental e escassez hídrica em bacias hidrográficas: Manancial do Rio das Araras - Araras, SP. Revista Brasileira de Recursos Hídricos [Internet]. 2015 [cited 2018 Jun 12];20(4):946-958. Available from: 10.21168/rbrh.v20n4.p946-958.

DE GROOT RS, WILSON MA, BOUMANS RMJ. [A typology for the classification, description and valuation of ecosystem functions, goods and services]. Ecological Economics [Internet]. 2002 [cited 2018 Jun 12];41(3):393-408. English. Available from: http://dx.doi.org/10.1016/S0921-8009(02)00089-7.

DEBOLINI M, SCHOORL JM, TEMME A, GALLI M, BONARI E. [Changes in agricultural land use affecting future soil redistribution patterns: a case study in Southern Tuscany (Italy)]. Land Degradation \& Development [Internet]. 2015 [cited 2018 Jun 12];26(6):574-586. English. Available from: https://doi.org/10.1002/ldr.2217.

DECRETO N.5.334 DE 6 DE JANEIRO DE 2005. Dá nova redação ao art. 21 e revoga o art. 22 do Decreto no 89.817, de 20 de junho de 1984, que estabelece as Instruções Reguladoras das Normas Técnicas da Cartografia Nacional. Diário Oficial da União (Brasília). 2005 Jan 07.

EHRLICH PR, MOONEY HA. [Extinction, substitution, and ecosystem services]. BioScience. 1983;33(4):248-254. English.

FUNDAÇÃO FLORESTAL. Governo do Estado de São Paulo. Plano de Manejo Estação Ecológica de Jatai [Internet]. São Paulo: Governo do Estado de São Paulo, 2013. 333p. [cited 2018 Jun 12]. Available from: http://fflorestal.sp.gov. br/files/2017/02/Volume-Principal.pdf.

GÓMEZ-BAGGETHUN E., DE GROOT R. Natural Capital and Ecosystem Services: The Ecological Foundation of Human Society. In: Harrison RM, Hester RE, editors. Ecosystem Services. Royal Society of Chemistry, 2010. p. 105-121.

INSTITUTO AGRONÔMICO - IAC. Levantamento Pedológico Semidetalhado do Estado de São Paulo. Quadrículas: Araras (SF-23-Y-A-II), Descalvado (SF-23-V-C-IV) Ribeirão Preto (SF-23-V-C-I) e São Carlos (SF-23-Y-A-I). Escala 1:100.000, 1981.

INSTITUTO BRASILEIRO DE GEOGRAFIA E ESTATÍSTICA - IBGE [Internet]. Brasília: Ministério do Planejamento, Orçamento e Gestão (BR) [cited 2018 Jun 12]. IBGE Cidades. Available from: https://cidades.ibge.gov.br/brasil/sp/ luis-antonio/panorama. 
INSTITUTO BRASILEIRO DE GEOGRAFIA E ESTATÍSTICA - IBGE. [Internet]. Brasília: Ministério do Planejamento, Orçamento e Gestão (BR) [cited 2018 Jun 12]. Censo 2010. Available from: https://censo2010.ibge.gov.br/.

INSTITUTO BRASILEIRO DE GEOGRAFIA E ESTATÍSTICA - IBGE. Manual Técnico de Uso da Terra [Internet]. 3th ed. Rio de Janeiro (Brasil): IBGE, 2013 [cited 2018 Jun 12]. Available from: https://biblioteca.ibge.gov.br/visualizacao/ livros/liv81615.pdf.

JAX K, BARTON DN, CHAN KMA, GROOT R, DOYLE U, ESER U, et al. [Ecosystem services and ethics]. Ecological Economics [Internet]. 2013 [cited 2018 Jun 12];93:260-268. English. Available from: http://dx.doi.org/10.1016/j.ecolecon.2013.06.008.

LEI N. 9.985 DE 18 DE JULHO DE 2000. Regulamenta o art. 225, § 1o, incisos I, II, III e VII da Constituição Federal, institui o Sistema Nacional de Unidades de Conservação da Natureza e dá outras providências. Diário Oficial da União (Brasília). 2000 Jul 19.

MARTINE G, ALVES JED. Economia, sociedade e meio ambiente no século 21: tripé ou trilema da sustentabilidade? Rev. bras. estud. popul. 2015;32(3):433-460.

MEDEIROS R, PEREIRA GS. Evolução e implementação dos planos de manejo em parques nacionais no estado do Rio de Janeiro. Rev. Árvore. 2011;35(2):279-288.

MILLENNIUM ECOSYSTEM ASSESSMENT. Statement from the Board: living beyond our means - natural assets and human well-being. [Internet]. 2005 [cited 2018 Jun 12]. Available from: www.millenniumassessment.org.

O'NEILL RV, KRUMMEL JR, GARDNER RH, SUGIHARA G, JACKSON B, DEANGELIS DL, et al. [Indices of landscape pattern]. Landscape Ecology. 1998;1.1(3):153-162. English.

OST F. A natureza à margem da lei: a ecologia à prova do direito. 4th ed. Lisboa: Instituto Piaget, 1998.

PIRES JSR, SANTOS JE. [Preliminary analysis of environmental impacts applied to a rural area of São Paulo State (Luiz Antônio, SP, Brazil)]. International Association for Impact Assessment. 1996;2:969-974. English.

SANTOS JE, NOGUEIRA F, PIRES JSR, OBARA AT, PIRES AMZCR. [The value of the Ecological Station of Jataí's ecosystem services and natural capital]. Rev. Bras. Biol. 2001;61(2):171-190. English.

SANTOS M. Espaço \& Método. 1st ed. São Paulo: Nobel, 1985.

SILVA DB. Sustentabilidade no Agronegócio: dimensões econômica, social e ambiental. Comunicação \& Mercado/ UNIGRAN. 2012;1(3):23-34.

TEIXEIRA AMG, SOARES-FILHO BS, FREITAS SR, METZGER JP. [Modeling landscape dynamics in an Atlantic Rainforest region: Implications for conservation]. Forest Ecology and Management. 2009;257(4):1219-1230. English.

TOPPA RH. Estrutura e diversidade florística das diferentes fisionomias de Cerrado e suas correlações com o solo na Estação Ecológica de Jataí, Luiz Antônio, SP [thesis]. São Carlos: Programa de Pós-Graduação em Ecologia e Recursos Naturais/UFSCar; 2004. 127p.

TREVISAN DP, MOSCHINI LE, MELLO BM. Avaliação da naturalidade da paisagem do município de São Carlos, São Paulo, Brasil. Revista Brasileira de Geografia Física. 2017;10(2):356-370.

TURNER MG. [Landscape ecology: the effect of pattern on process]. Annual review of ecology and systematics. 1989;20(1):171-197. English.

UNITED STATES. United States Geological Survey (USGS) [Internet]. Imagens LANDSAT [cited 2018 Jun 12]. Available from: http://earthexplorer.usgs.gov/.

WRBKA T, ERB KH, SCHULZ NB, PETERSEILA J, HAHNA C, HABERL H. [Linking pattern and process in cultural landscapes: An empirical study based on spatially explicit indicators]. Land Use Policy. 2004;21:289-306. 